\title{
Anatomical Basis of Ossified Ligaments of Sphenoid Bone in Diagnosis
}

\author{
Agarwal, S. *, Agarwal, S. K. \& Pant, M. K. \\ Department of Anatomy, Government Doon Medical College, Dehradun, India
}

\begin{abstract}
Study the etiology and morphology of ossified ligaments of Sphenoid bone and its clinical manifestations which are of great significance to surgeons, neurosurgeons etc. 54 dried skulls of unknown age and sex were studied examining both the superior and inferior surfaces of the base of skull. The study showed 4 complete and 10 incomplete ossified Pterygospinous ligament. Total 18 ossified Pterygoalar ligament with 7 skulls showing bilaterally. 2 skulls Showed all the three ossified Carotico-clinoid, Interclinoid and Petrosphenoid ligaments seen bilaterally are unique. Relevant Knowledge of Anatomy of ossified ligaments of Sphenoid bone great helps to Neurosurgeons, Forensic experts and radiologists as well.
\end{abstract}

Keywords: Pterygospinous Ligament, Pterygoalar Ligament, Pterygoid Processes, Petrosphenoid Ligament.

\section{Introduction}

Skull comprises of skeleton of head and face. Because of its structural complexity, it is divisible into various Normas for its study purpose.

Norma Basalis, being still more complex divisible into anterior, middle and posterior parts. The middle portion mainly comprises of the Sphenoid bone wedging between the Frontal (in front), Temporal (on each side) and occipital (at back) bones. The Sphenoid bone consists of a body in the centre, paired wings diverging laterally from the body as greater and lesser wings and two pterygoid plates as medial and lateral pterygoid plates descends vertically down from the pterygoid processes between the body and the greater wing of sphenoid bone.

Embryologically, the sphenoid is evolved partly from the cartilage. The body, the lesser wings and the medial parts of the greater wings (alisphenoid) developed from the cartilage while rest of the alisphenoids and the pterygoid processes, with the exception of the pterygoid hamuli, are ossified in membrane. At $1^{\text {st }}$ year of life all the parts of sphenoid bone coalesce to form single bone. At the $7^{\text {th }}$ week, the primitive base of the skull is formed by the cartilaginous tissue transforming at the level of the basisphenoid and basiocciput.

Calcification in the pineal gland, meninges of the brain and ligaments of the skull is seen normally but calcification is also seen in large number of abnormal conditions, whose investigations, diagnosis and clinical manifestations are of great importance to surgeons, neurosurgeons, radiologists along with anatomists and forensic experts. Moreover the calcifications are seen in long standing cases rather in rapid occurring diseases.

Various ligaments connect the sphenoid bone to its own different parts (intrinsic ligaments) as well as other neighbouring bones -

The Pterygospinous ligament, joining between the spine of sphenoid with the prominent projection on the upper part posterior edge of the lateral pterygoid plate. The ligament may be short or 2 ligaments as long and short bands (probably modified fibres of lateral pterygoid muscle), may be present undergoing ossification occasionally presenting as a bony bar related to Foramen Ovale and its issuing nerves $^{1}$. The ossification may be complete or incomplete results in formation of foramen named Foramen of Cavinini. Italian anatomists F. Cavinini (1805-1844) first coined and described the term pterygospinous ligament or ligament of Cavinini in $1835^{2}$.

The Pterygoalar ligament (Hyrtl-Calori's ligament)The Sphenomandibular ligament (Remnant of Meckle,s cartilage) divided into two independent parts as the inter pterygoid fascia and an innominate ligament first described by $\mathrm{Hyrtl}^{3}$, lateral to interpterygoid fascia ,the fibrous sheath attached to the infra temporal surface of the greater wing of sphenoid and the root of lateral pterygoid plate, was stated by Rouviere and Delmas ${ }^{4}$. Ossification of this ligament occasionally forms Foramen Pterygoalar (porus crotaphitico-buccinatorius) may be responsible for the compression of the branches of the mandibular division of the trigeminal nerve.

The Caraticoclinoid ligament and the Interclinoid ligamentThe bony sphenoidal points to which the dura mater is 
attached are known as Clinoid processes: The Anterior clinoid process extends from the root of lesser wing of sphenoid on each side, the Posterior as an extension from the superolateral angles of the dorsum sellae, while the Middle, often absent, is a small tubercle medial to carotid groove on each side. These processes are connected by Interclinoid ligaments which may be ossified ${ }^{5}$.The cavernous sinus lies lateral to and below the interclinoid ligament joining the anterior and the posterior clinoid processes. The osseous bridge between the anterior and the middle clinoid processes forms the caratico-clinoid bridge, encircling the internal carotid artery as Caraticoclinoid foramen of Henle, may cause the compression or the tightening of the artery.

Petrosphenoid ligament(Gruber,s ligament or Petroclinoid ligament or petrolingual ligament) Gruber ${ }^{6}$ described about 2 bony spurs at the attachment zone of this ligament at the posterior petrosal process of the sphenoid bone, arising from the superolatral angle of the dorsum sellae of the Turkish saddle and the posterior sphenoidal process of petrosal part of temporal bone. Both these spurs meet at the beginning of the groove for the inferior petrosal sinus or above the semisulcus of the body of sphenoid bone. The space below the ligament known as Dorello's Canal ${ }^{7}$ where lies the abducent nerve with its arachnoid sheath. Strobel ${ }^{8}$ (1980) found superior as well as inferior sphenopetrosal ligaments while dissecting. The inferior petrosal ligament is the connective tissue fibres run sideways above and medial to the sphenoid lingula and the adjacent parts of sphenoid bone upto the anterior process of the petrous temporal, described by Fournier ${ }^{9}$ as the petro apex triangle and from the periosteum of carotid canal. Ligament of Gruber as well as Dorello's canal both causes abducent nerve palsy in patients with severe middle ear infections, raised intra cranial pressure and Gradenigo's syndrome ${ }^{10}$ that includes petrous apicitis

The calcification of above ligaments and their causes may vary involving the boundaries of sphenoid bone as under-

Gliomas: The commonest cause of intracranial calcification above and below the tentorium. The optic nerve and the hypothalamus gliomas lead to the erosion of clinoid processes.

Craniopharyngioma: Intracranial tumor affecting sella turcica to variable degree More than $50 \%$ of craniopharyngioma occurs in children between 8 to 12 years of age and rest involving middle aged adults.

Meningiomas: Tumors of the vault or to the base of skull associated with many bone changes either hyperostosis or erosion. Neurofibromatosis is seen rarely.
Chondromas: Though rare but associated with the choroid plexus of the lateral ventricle.

Chordoma: involving dense calcification around the sella and basal erosion.

Pinealoma: Tumours involving pineal gland

Pathological calcifications in sellar or parasellar region may be related to vascular anomalies like aneurysms of internal carotid artery, circle of Willis or basilar artery; atherosclerosis of internal carotid artery, A V malformations; infections like tuberculous meningitis and neoplasms (Chordoma, Teratoma, craniopharyngioma, osteoma, meningioma, optic chiasm glioma etc).

Radiation Damage: Calcification in scattered form seen in long time after irradiation of the brain eg. C.T. scan.

\section{Material \& Methods}

A total of 54(108 sides) dried human skulls of unspecified age and sex belonging to the Department of Anatomy, Government Doon Medical College, Dehradun, India. Close examination of both the superior and inferior surfaces of the base of skull were carried out to find out ossified ligaments of sphenoid bone for the following-

Location of the ligament (right, left or bilateral)

Degree of ossification (Complete or incomplete)

Measurements of the ossified ligament/ Foramen formed

The data was tabulated. All the measurements were made using Vernier Calipers by the same person to avoid interobserver error.

Calculation of the percentage $(\%)$ of the skulls with the presence of various ossified ligaments of the sphenoid bone was done.

\section{Result}

In the present study out of 54 dried human skulls examined, 26.66\% skulls showed the presence of ossified Pterygospinous ligament of which $6.66 \%$ skulls showed complete ossification with Pterygospinous foramen formation with length $2 \mathrm{~mm}$ and width $1 \mathrm{~mm}$. $33.33 \%$ skulls presented ossified pterygoalar ligament. Out of $33.33 \%$, $13.33 \%$ showed bilateral ossified pterygoalar ligament with the length as $5 \mathrm{~mm}$ and the width $3 \mathrm{~mm}$ of the Pterygoalar foramen. Ossified Carotico-clinoid ligament present in 36.66 percent of 54 skulls. $72.22 \%$ and $66.66 \%$ of skulls presented with ossified both complete and incomplete Petrosphenoid and Interclinoid ligaments respectively. (table 1)

The complete or incomplete ossification of above ligaments and formation of various bony foramina establishing 
important relationships with numerous neurovascular bundles are capable of creating important clinical manifestations which are bound to confuse anaesthetists, radiologists, oro- maxillofacial surgeons and clinical surgeons to explore new approaches and techniques to tackle imposed difficult situations.

Table 1: Prevalence and measurement of various ossified ligaments of Sphenoid bone.

\begin{tabular}{|c|c|c|c|c|c|c|c|c|}
\hline \multirow{2}{*}{ Ligaments } & \multirow{2}{*}{ Complete } & \multirow{2}{*}{ Incomplete } & \multirow{2}{*}{ Total } & \multirow{2}{*}{ Right } & \multirow{2}{*}{ Left } & \multirow{2}{*}{ Bilateral } & \multicolumn{2}{|c|}{$\begin{array}{c}\text { Measurements of complete } \\
\text { ligaments (in } \mathrm{mm} \text { ) }\end{array}$} \\
\hline & & & & & & & $\begin{array}{l}\text { Maximum } \\
\quad(\mid \times \mathbf{b})\end{array}$ & $\underset{(\mathbf{1} \times \mathbf{b})}{\operatorname{Minimum}}$ \\
\hline Pterygospinous & 04 & 10 & 14 & 03 & 03 & 04 & $10 \times 2$ & $6 \times 1.5$ \\
\hline Pterygoalar & 07 & 11 & 18 & 02 & 02 & 07 & $13 \times 3.5$ & $7 \times 4$ \\
\hline Caraticoclinoid & 06 & 14 & 20 & 06 & - & 07 & $7 \times 2$ & $5 \times 2$ \\
\hline Interclinoid & 05 & 31 & 36 & - & 08 & 14 & $11 \times 2$ & $5 \times 2$ \\
\hline Petrosphenoid & 08 & 31 & 39 & 05 & 08 & 13 & $9 \times 2$ & $6 \times 2$ \\
\hline
\end{tabular}

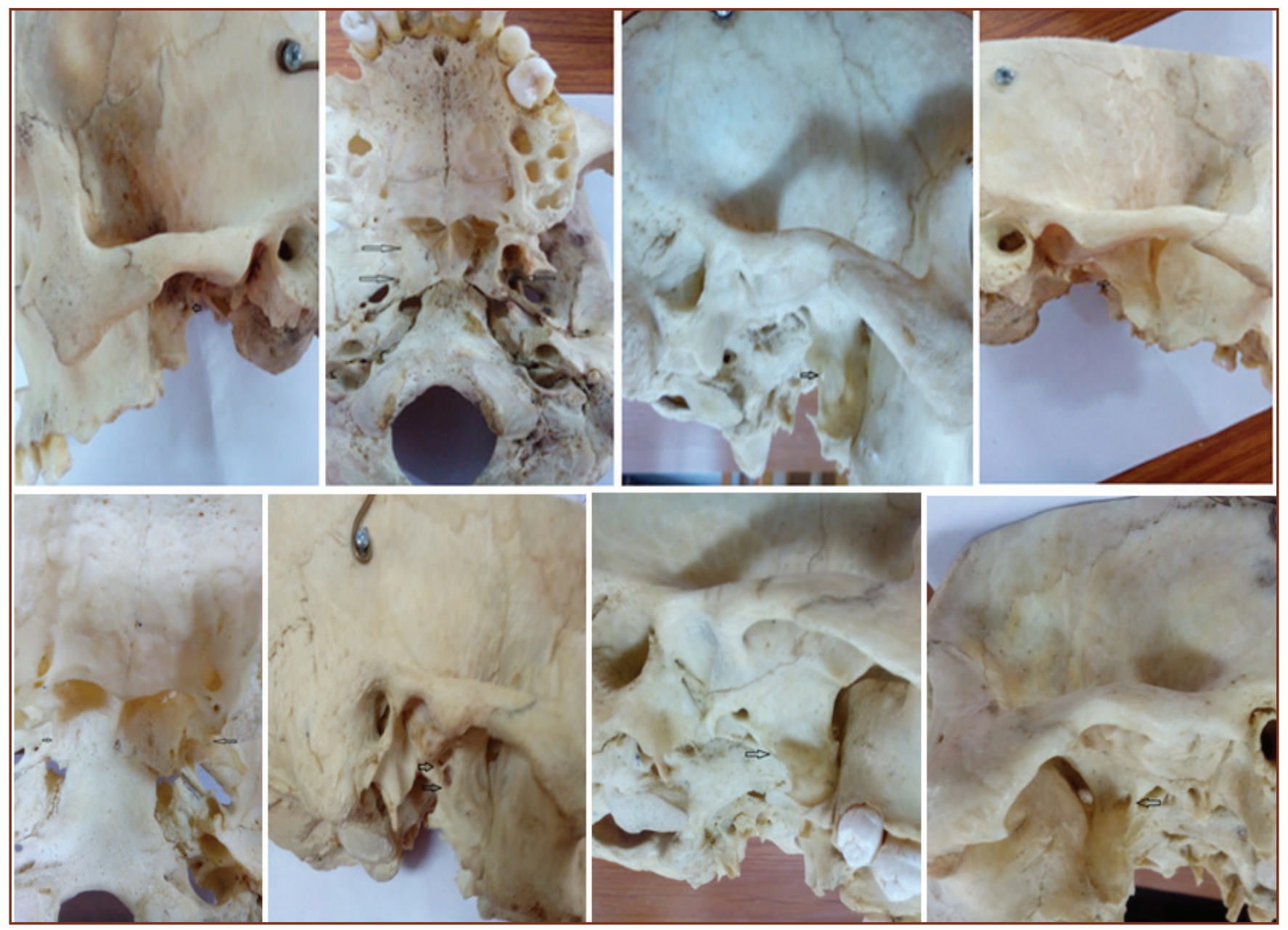

Fig.1: Arrows showing complete ossified Pterygospinous ligaments with formation ofPterygospinous foramina. 

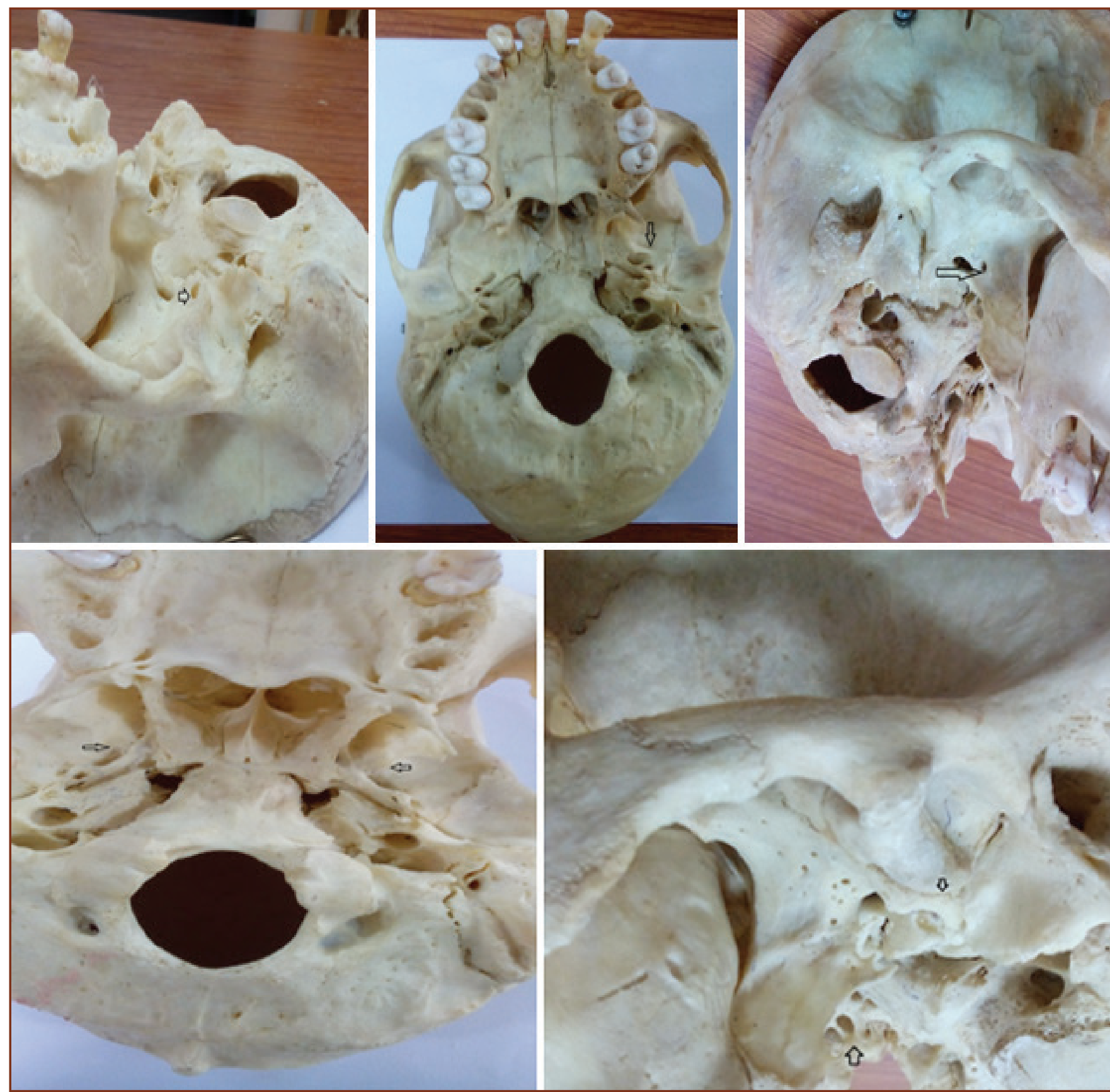

Fig. 2: Arrows showing complete ossifiedPterygoalar Ligaments with formation of Pterygoalar foramina. 


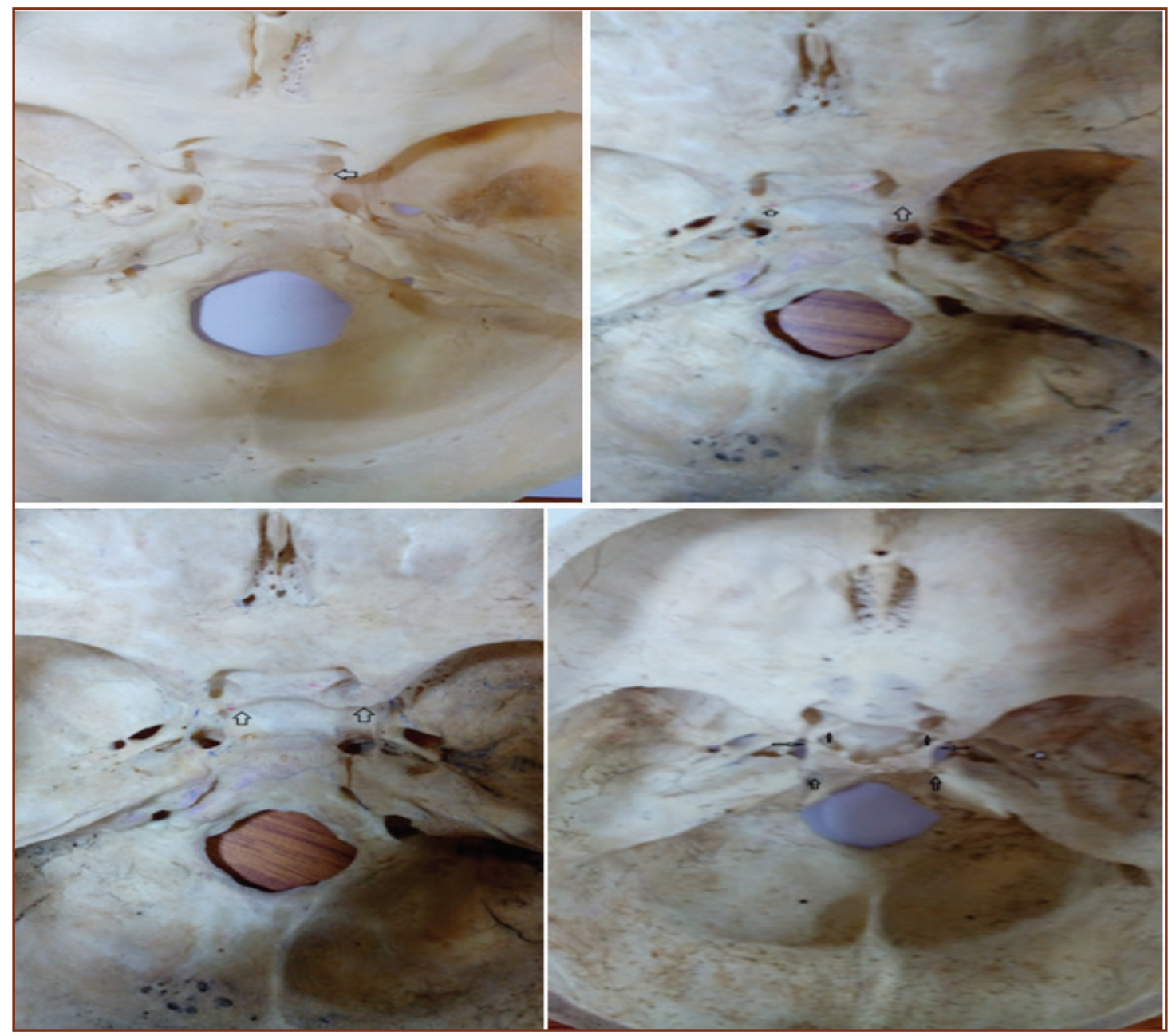

Fig. 3: Arrows showing complete ossified Carotico-clinoid ligament with formation of its foramen.

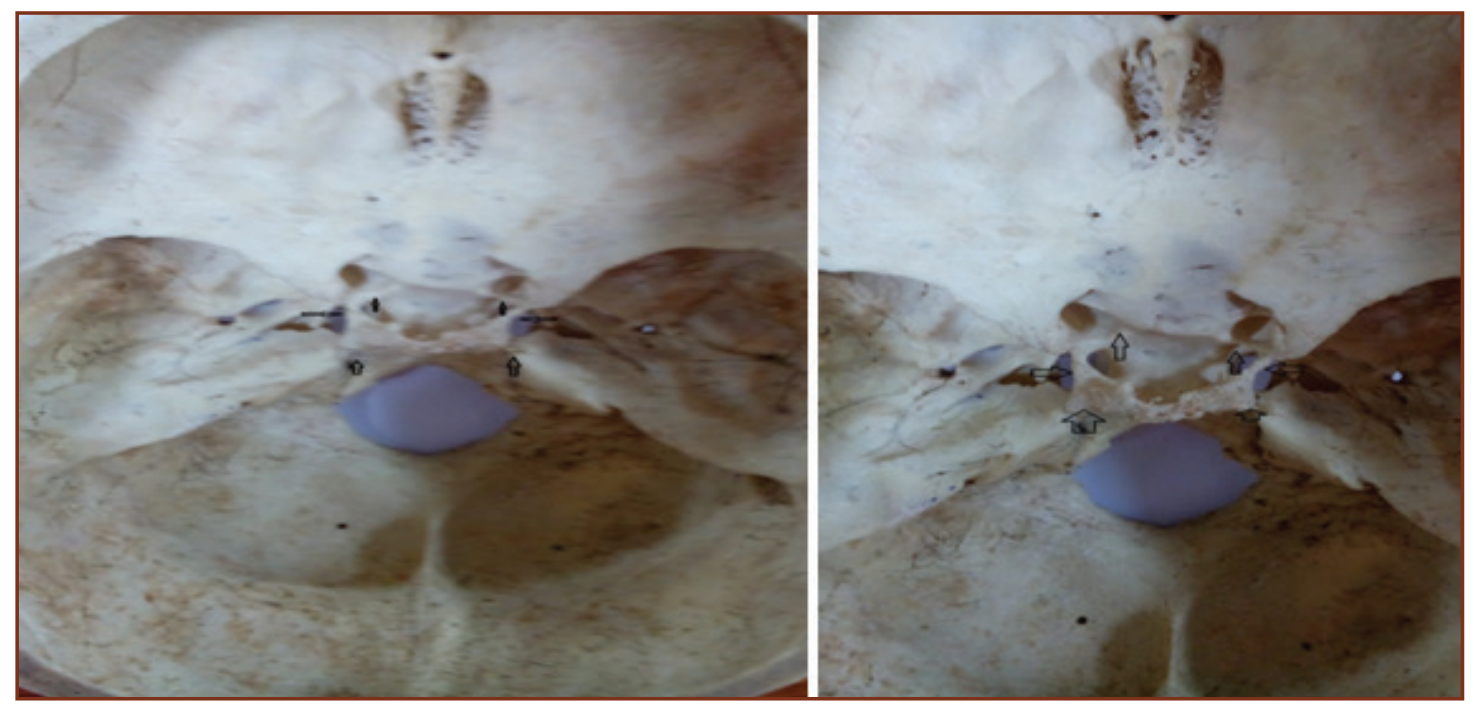

Fig. 4: Above directed arrows showing ossified Carotico-clinoid ligament with its foramina formation bilaterally, below arrows showing ossified Petrosphenoid ligament bilaterally with formation of foramina and side arrows showing bilaterally ossified Interclinoid ligaments.

Annals of Advanced Medical Science, Vol. 2; Issue 2, April-June, 2018 

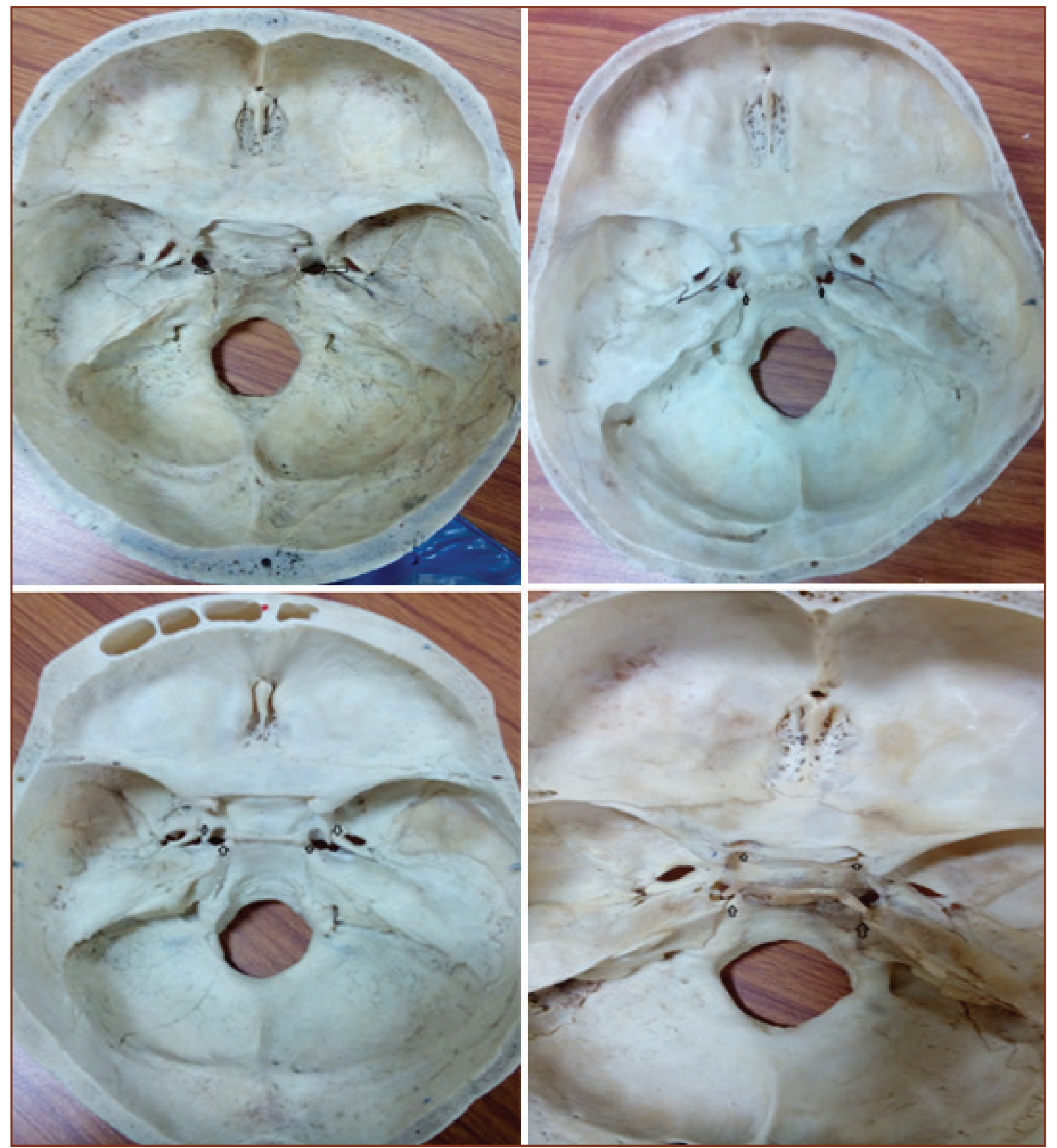

Fig. 5: Arrows showing ossified Petrosphenoid ligament bilaterally. 


\section{Discussion}

The ligaments are the fibrous connective tissue bands not only joining the adjacent bones but also delimiting their movements when ossified as well as producing severe complications on compressing upon neurovascular structures passing underneath them.

Antonopoulou, M. et $\mathrm{al}^{11}$. (2008) studied the existence of the Pterygospinous and pterygoalar bony bridges and foramina in 50 Greek dry skulls and showed complete ossification of Pterygospinous ligament in only 1 skull bilaterally and incomplete in 25 out of 100 cases while completely ossified pterygoalar in 1 and incompletely ossified in 7 out of 100 observations.

Suazo Galdames et $\mathrm{al}^{12}$ (2010) evaluated 312 Brazilian skulls for complete and incomplete ossifications of pterygoalar ligament and obtained incidences of 3.84 and $22.43 \%$ respectively.

Shinde V. S. et $\mathrm{al}^{13}$ (2011) studied the ossification of Pterygospinous ligament in 65 human adult skull bones and observed incompletely ossified ligament in 2 skulls with 1 on left and other on right side.

Rossi A.C. et al ${ }^{14}$ (2011) evaluated 183 Brazilian adult dry human skulls for complete or partial ossification of the pterygoalar ligament and obtained incidence of $2.73 \%$. Out of which occurrence of $0.54 \%$ unilaterally, left incomplete ligament and $2.18 \%$ complete ligament ossification on the right side.

Aggarwal B. et a $1^{15}$ (2012) studied 67 dried skulls (134 sides) for the occurrence of ossified ligaments and found ossified ligaments in 51 sides of skulls. The ossified caroticoclinoid ligament in 22 sides, out of which 4 sides complete and 18 sides incomplete. The interclinoid ligament was found unilaterally in 9 sides, of which 7 incomplete and 2 sides complete. The ossified petrosphenoid was present unilaterally 7 sides, 4 sides incomplete and 3 sides complete. The Pterygospinous ligament ossification seen in 13 sides, 9 incomplete and 4 complete.

Solan S. \& Reddy G.K. ${ }^{16}$ (2014) studied 50 dried human skulls in Orissa for the presence of ossified Pterygospinous ligament. They found only 1 skull showed incomplete ossified ligament bilaterally.

Kamath K. \& Kamath V. ${ }^{17}$ (2015) reported a case report on bilateral complete caraticoclinoid bridges and in addition a completely ossified petrospenoidal ligament during routine osteology classes for first year medical students in Karnataka and presented it as a unique morphological event with neurovascular implications relevant for neurosurgeons and radiologists.

The Present study showed 4 complete and 10 incomplete ossified Pterygospinous ligament. Total 18 ossified Pterygoalar ligament with 7 skulls showing bilaterally. In 2 skulls the presence of all the three ossified Carotico-clinoid, Interclinoid and Petrosphenoid ligaments seen bilaterally is unique in itself. 20 ossified Caraticoclinoid ligaments, 36 ossified Interclinoid ligaments and 39 Petrosphenoid ligaments both complete and incomplete out of 54 skulls with 108 sides seen.

Relevant knowledge of these anatomical variants is of great help to neurosurgeons, dental surgeons as well as clinicians in their day to day practice.

\section{Conclusion}

The presence of various ligaments of sphenoid bone as an anatomical rare variant inadvertently affecting the neurovascular structures nearby causing hindrance in various surgical approaches for anaesthetists, maxillofacial and dental surgeons and neurosurgeons as well as leading to various clinical manifestations. However one should exclude such ossified structures by various radiological procedures rather than taken by surprise later on.

\section{References}

1. Breathnach, A. S. Frazer,s Anatomy of the human skeleton. Sixth edition,1965,pg 204.

2. Tebo, H. G. The Pterygospinous bar in panoramic roentgenography. Oral Sergury, Oral Medicine, Oral Pathology. 1968; 26 (5); 654-657.

3. Hyrtl J. Uber den porus crotaphitico Buccinatorius beim Menschen, Sitzungsb, D. K. Akad, D. Wissensch. Mathnaturw.Cl. Wien. 1862; 46:111-15.

4. Rouviere, H. \& Delmas, A. Anatomia Humana Descriptiva, Topografica Y Functional. Barcelona, Masson, 1999. V.3.

5. Breathnach, A. S. Frazer,s Anatomy of the human skeleton. Sixth edition, 1965, pg 168,200.

6. Gruber, W. (Contributions to the anatomy of the skull base). Mem Acad Imp Sci St. Peterbourg 13:1-34, 1869 (Ger).

7. Dorello, P.(Considerations concerning the cause of temporary paralysis of the abducent in middle ear inflammation.) Atti della Clinica Oto-Rino-Laringoiatrica della R. Universita di Roma 3: 209-217, 1905 (Ital).

8. Lang, J. Skull Base and Related Sructures. Atlas of Clinical Anatomy, Schattauer Verlag, Germany, 2nd edition, page. 86.

9. Fournier, H. D., Mercier, P. \& Roche, P. H.Surgical Anatomy of the petrous apex and petroclival region. Advances andTechnical Standards in Neurosurgery, Springer Verlag, Austria, 2007, vol. 32. 
10. Gradenigo, G. :( On a particular syndrome of intracranial otitic complications: Paralysis of the abductor of otitic origin.) Annales des Maladies de 1,Oreille, du Larynx, du Nez et du pharynx30:120-152,1904(Fr).

11. Antonopoulou M, Piagou M, Anagnostopoulou S. An anatomical study of the pterygospinous and pterygoalar bars and foramina-their clinical relevance. J. Craniomaxillofac. Surg. 2008; 36:104-108.

12. SuazoG.I, Zavando M.D., Smith R.L. Anatomical study of Pterygospinous and pterygoalar bony bridges and foramen in dried crania and its clinical relevance. Int JMorphology. 2010; 28(2):405-408.

13. Vijayakumar Shankar Sindhe, Mallikarjun. M, Raveendra patil. A study on ossified pterygospinous ligament. Journal of Clinical and Diagnostic Research. October 2011;5(5): 978-979.
14. Rossi, A. C., Freire, A. R., Manoel, C., Prado, F. B., Botacin, P. R. \& Caria, P.H. F. Incidence of the ossified pterygoalar ligament in Brazilian human skulls and its clinical implications. J. Morphol. Sci., 2011, vol.28:1, p. 69-71.

15. Agarwal, B., Gupta M, Kumar H. Ossified ligaments of the skull. J Anat Soc India. 2012; 61(1):37-40.

16. Solan, S. \& Reddy, G. K. Anomalous Ossified Pterygospinous Ligament in Eastern Zone- A case study. IOSR Journal of Dental and Medical Sciences. April.2014, vol. 13:4 ver.1.;p. 60-62.

17. Kamath, K. \& Kamath, V. Ossification of Caroticoclinoid and Petrosphenoidal Ligaments of skull. International Journal of Anatomy and Research, Int J Anat Res 2015, Vol 3(2):1039-42.

*Corresponding author:

Dr. Sumita Agarwal, Flat no. S-202, Platinum Paradise Residency, 45, Kishanpur, Canal road, Dehradun (Uttarakhand)-248001.India

Phone: +91 8393024688

Email: docsumita29@gmail.com

Financial or other Competing Interests: None. 